\title{
Miniaturized Dual Bandstop Filter using CRLH Transmission Line
}

\author{
Samar Refaat \\ Benha Faculty of Engineering \\ Benha Univeristy \\ Benha ,Egypt
}

\author{
Amr A. Al-Awamry \\ Benha Faculty of Engineering \\ Benha University \\ Benha,Egypt
}

\author{
A. A. Mitkees \\ MTC \\ Cairo ,Egypt
}

\begin{abstract}
Design of a dual wide bandstop filter is proposed based on Composite Right and Left-Handed Transmission-line (CRLHTL) . Two stop bands with center frequencies of $8.3 \mathrm{GHz}$ and $12.9 \mathrm{GHz}$ are achieved with fractional bandwidths $57.8 \%$ and $32.5 \%$ respectively. Spiral interdigital capacitors and stub inductors are employed to designed filter. The proposed bandstop filter provides low passband insertion loss, better attenuation in stopbands, and low cost. The total filter size is about $7.8 \mathrm{~mm} \times 15.1 \mathrm{~mm}$ which is very compact compared to other metamaterial and conventional microstrip filters. Filter is also fabricated and measured to demonstrate the performance matched with simulation results.
\end{abstract}

\section{Keywords}

Composite Right and Left-Handed Transmission-line (CRLHTL), Dual band filter, Metamaterials, Spiral interdigital capacitor, Stub inductors.

\section{INTRODUCTION}

Bandstop filters are essential building blocks in wireless systems. They play an important role of filtering out unwanted signals. Compact design, high rejection in stopbands, and high selectivity are important characteristics of bandstop filters. There are different methods to design these filters, it is designed by using quarter-wavelength shortcircuited stubs[11], another bandstop filters using steppedimpedance open-circuited stubs are designed in papers [5][6]-[8]-[10]- [12] but large size and narrow stopband are problems of these designed filters.

In [14], a dual bandstop filter is achieved by using threesection stepped impedance resonators (SIRs), or a dual-mode loop resonator [15]. A compact dual band BSFs may also be realized by combining a spur-line structure and a rectangle slot [16]. Dual band BSF composed of meandered slot defected microstrip structure and simplified spiral microstrip resonator is developed in [17] to obtain independently controlled stopbands and improved spurious response. Another methods and structures have been proposed [18-21]. In [18], two square SRRs are placed on the same transverse plane realizing two independent reject bands.

A compact dual band bandstop filter with sharp rejection using transversal signal interaction, consisting of a transmission line path and a cascaded coupled line path, is proposed [19]. In [20],dual and tri band bandstop filters are designed using I-stubs embedded within a meandered defected microstrip structure. Also, a dual band bandstop filter is based on open stubs and two equivalent T-shaped lines [21].

Early in 1968, Veselago first introduced the concept of lefthanded material (LHM) with negative permittivity and negative permeability [13]. In his paper, Veselago speculated on the possible existence of LHMs and anticipated their unique electromagnetic properties. First artificial LHM composed of thin wire cylinder and split-ring resonators (SRR) was realized by researchers such as Pendry et al. [9]Smith et al.[7]. SRR-based LHM only exhibit LH properties around the resonance of SRR. Therefore, realization of LHM using SRRs is not practical for microwave engineering applications as narrow-band and lossy due to requirement of operation near SRR resonance. To overcome drawbacks of SRR-based LHM, several researchers [1]-[4] soon realized that a transmission line can be used to realize a non-resonant LHM. LH transmission line approach is based on dual configuration of a $\mathrm{RH} /$ conventional transmission line, a composite right/left handed transmission line (CRLH-TL) structure provides left-handed (LH) and right-handed $(\mathrm{RH})$ characteristics was first proposed by Caloz and Itoh [2]. New miniaturized antennas and microwave components/devices can be created for wireless communications and defense industries using LHM .

In this paper, A dual compact composite right/left handed transmission line (CRLH-TL) bandstop filter is designed. CRLH-TL structure is implemented in the form of spiral interdigital capacitors and stub inductors and our novel dual stop band filter has two stop bands with center frequencies of $8.3 \mathrm{GHz}$ and $12.9 \mathrm{GHz}$ and fractional bandwidth (FBW) $57.8 \%$ and $32.5 \%$,respectively. Total filter size is about $7.8 \mathrm{~mm} \times 15.1 \mathrm{~mm}$

The remaining content of this paper is organized as follows. In section 2 ,equivalent circuit model of a CRLH transmission line structure and its theory. In Section 3, design of proposed filter. In section 4, simulation and measurement results of fabricated filter. Finally, conclusion of this work is presented in section 5 .

\section{EQUIVALENT CIRCUIT MODEL OF A CRLH TRANSMISSION LINE STRUCTURE AND ITS THEORY}

Left-handed materials(LHMs), are referred as metamaterials, which have simultaneously negative permittivity $(\varepsilon)$ and negative permeability $(\mu)[13]$. LHMs are dual of right-handed materials (RHMs) / conventional materials, a pure LH transmission line doesnot exist alone without RH transmission line because of RH parasitic effects, so combination of $\mathrm{LH}$ and RH structure form a composite right/left handed (CRLH) transmission line. Equivalent circuit model of Symmetric CRLH unit structure is shown in Fig.1 and propagation constant for a lossless CRLH transmission line is given by[3] 


$$
\beta_{\mathrm{CRLH}}=s(\omega) \sqrt{\omega^{2} \mathrm{~L}_{\mathrm{R}} \mathrm{C}_{\mathrm{R}}+\frac{1}{\omega^{2} \mathrm{~L}_{\mathrm{L}} \mathrm{C}_{\mathrm{L}}}-\left(\frac{\mathrm{L}_{\mathrm{R}}}{\mathrm{L}_{\mathrm{L}}}+\frac{\mathrm{C}_{\mathrm{R}}}{\mathrm{C}_{\mathrm{L}}}\right)}
$$

where:

$$
s(\omega)= \begin{cases}-1 & \text { if } \omega<\omega_{\Gamma 1}=\min \left(\omega_{\text {se }}, \omega_{\text {sh }}\right) \\ +1 & \text { if } \omega>\omega_{\Gamma 2}=\max \left(\omega_{\mathrm{se}}, \omega_{\mathrm{sh}}\right)\end{cases}
$$

,and

$$
\begin{aligned}
& \omega_{\text {se }}=\frac{1}{\sqrt{L_{R} C_{L}}} \\
& \omega_{\text {sh }}=\frac{1}{\sqrt{L_{L} C_{R}}}
\end{aligned}
$$

$\omega_{\text {se }}, \omega_{\text {sh }}$ are series and shunt resonances of CRLH series and shunt branches respectively. A dispersion diagram for a CRLH unit-cell is shown in Fig. 2. When $\omega_{\text {se }}$ and $\omega_{\text {sh }}$ are not equal, stop-band is generated between transition from $\mathrm{LH}$ to RH propagation (unbalanced case). In balanced case, $\omega_{\mathrm{se}}=\omega_{\mathrm{sh}}$ and no stop-band between transition from LH to RH. Right and Left handed cutoff frequencies $\omega_{\mathrm{CR}}, \omega_{\mathrm{CL}}$ respectively are given by[3]

$$
\begin{gathered}
\left(\omega_{\mathrm{CR}}\right)_{\text {balanced }}=\frac{2}{\sqrt{\mathrm{L}_{\mathrm{R}} \mathrm{C}_{\mathrm{R}}}} \\
\left(\omega_{\mathrm{CL}}\right)_{\text {balanced }}=\frac{1}{2 * \sqrt{\mathrm{L}_{\mathrm{L}} \mathrm{C}_{\mathrm{L}}}} \\
\left(\omega_{\mathrm{CR}}\right)_{\text {unbalanced }}=\sqrt{\frac{\left[\mathrm{k}+\left(2 / \omega_{\mathrm{L}}\right)^{2}\right] \omega_{0}^{2}+\sqrt{\left[\mathrm{k}+\left(2 / \omega_{\mathrm{L}}\right)^{2}\right]^{2} \omega_{0}^{4}-4}}{2}} \\
\left(\omega_{\mathrm{CL}}\right)_{\text {unbalanced }}=\sqrt{\frac{\left[\mathrm{k}+\left(2 / \omega_{\mathrm{L}}\right)^{2}\right] \omega_{0}^{2}-\sqrt{\left[\mathrm{k}+\left(2 / \omega_{\mathrm{L}}\right)^{2}\right]^{2} \omega_{0}^{4}-4}}{2}}
\end{gathered}
$$

where:

and

$$
k=L_{R} C_{L}+L_{L} C_{R}
$$

$$
\begin{aligned}
& \omega_{\mathrm{R}}=\frac{1}{\sqrt{\mathrm{L}_{\mathrm{R}} \mathrm{C}_{\mathrm{R}}}} \\
& \omega_{\mathrm{L}}=\frac{1}{\sqrt{\mathrm{L}_{\mathrm{L}} \mathrm{C}_{\mathrm{L}}}}
\end{aligned}
$$

A CRLH TL structure has a band-pass when $\omega_{\mathrm{CL}}<\omega_{\mathrm{CR}}$ and has a band-stop characteristic when $\omega_{\mathrm{CL}}>\omega_{\mathrm{CR}}$. The centre frequency of band-pass or band-stop can be given by

$$
\omega_{0}=\sqrt{\omega_{\text {se }} \omega_{\text {sh }}}=1 / \sqrt[4]{\mathrm{L}_{\mathrm{R}} \mathrm{C}_{\mathrm{R}} \mathrm{L}_{\mathrm{L}} \mathrm{C}_{\mathrm{L}}}
$$

and a characteristic impedance $\left(\mathrm{z}_{0}\right)$ of balanced and unbalanced CRLH are given by (13-14) respectively,

$$
\begin{aligned}
& \left(\mathrm{z}_{0}\right)_{\text {balanced }}=\sqrt{\frac{\mathrm{L}_{\mathrm{L}}}{\mathrm{C}_{\mathrm{L}}}}=\sqrt{\frac{\mathrm{L}_{\mathrm{R}}}{\mathrm{C}_{\mathrm{R}}}} \\
& \left(\mathrm{z}_{0}\right)_{\text {unbalanced }}=\sqrt{\frac{\mathrm{Z}}{\mathrm{Y}}}
\end{aligned}
$$

where:

$\mathrm{Z}$ and $\mathrm{Y}$ are a series branch impedance and a shunt branch admittance in a CRLH unit cell, respectively.

Above equations are used to get $\mathrm{L}$ and $\mathrm{C}$ parameters when cutoff frequencies are known or used to get cutoff frequencies when circuit parameters are given.

\section{DESIGN OF PROPOSED DUAL BANDSTOP FILTER}

A microstrip implementation of a CRLH-TL composed of interdigital capacitance and shorted stub inductance is proposed here .Structure of proposed dual bandstop filter is shown in Fig. 3. It is represented by a symmetric unbalanced CRLH-TL unit cell ( $\left.\omega_{\mathrm{se}} \neq \omega_{\mathrm{sh}}\right)$,so filter has two bands. Proposed filter consists of two spiral interdigital capacitor represented $\mathrm{C}_{\mathrm{L}}$ and shorted stub between them represented $\mathrm{L}_{\mathrm{L}}$ in a symmetric CRLH-TL unit (fig.1).Spiral interdigital capacitor is used to realize miniaturization compared to original interdigital capacitor, also Shorted stub is bent as a meander line coil to reduce total size. So, the filter is less size than other conventional bandstop filters.

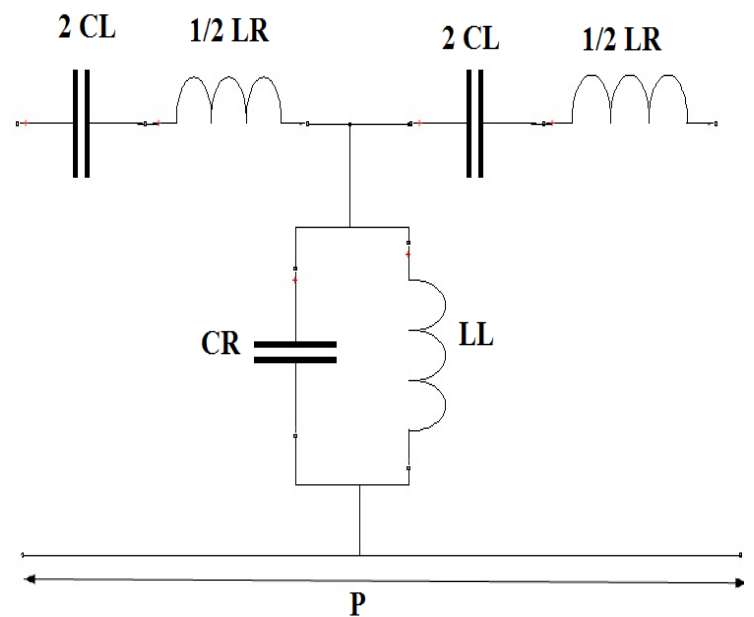

Fig. 1: Equivalent circuit of symmetric unit cell of a CRLH TL

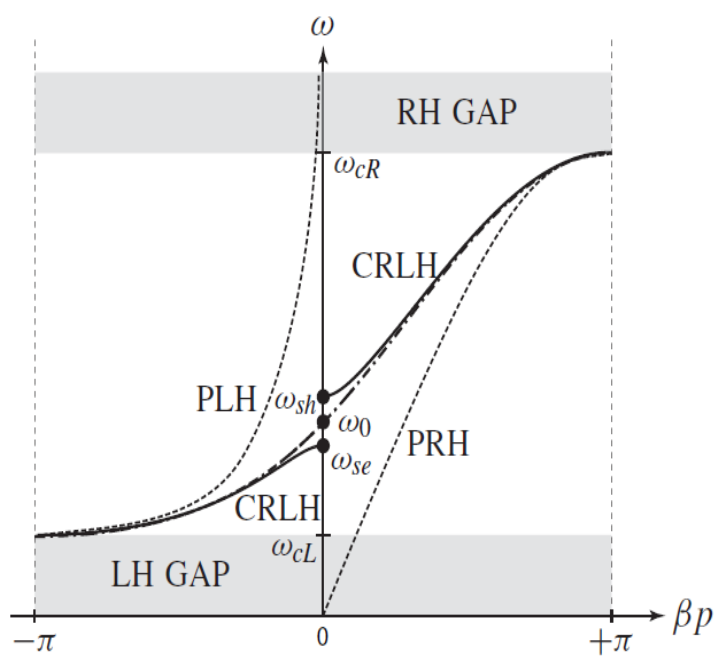

Fig. 2: A dispersion diagram for a CRLH unit-cell 


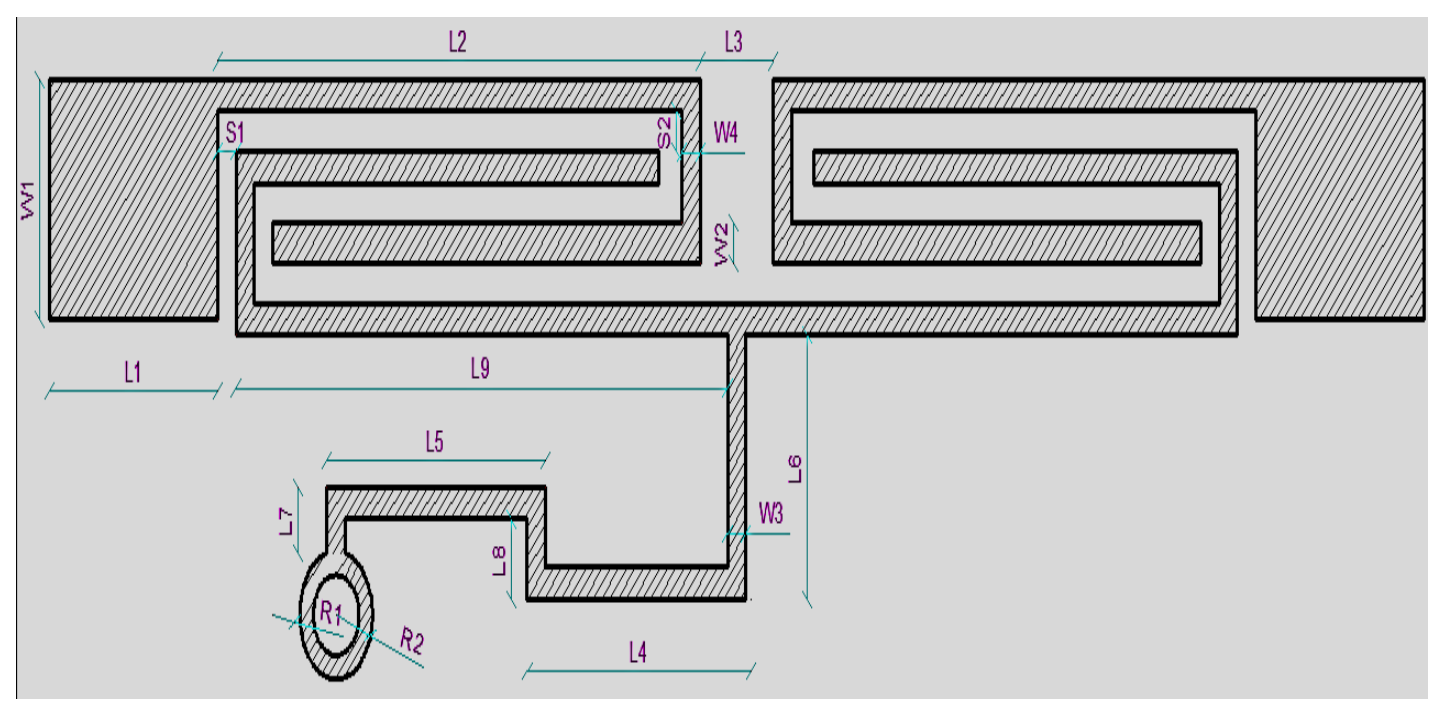

Fig 3:The structure of dual band BSF

\section{SIMULATION AND MEASUREMENT RESULTS OF THE FILTER}

A dual proposed bandstop filter is constructed on substrate Rogers $5880 \quad(\varepsilon \mathrm{r}=2.2$ and $\mathrm{h}=0.508 \mathrm{~mm})$ with size $7.8 \mathrm{~mm} \times 15.1 \mathrm{~mm}$ and dimensions of proposed filter are :

\begin{abstract}
$\mathrm{Wl}=1.5 \mathrm{~mm}, \quad \mathrm{Ll}=1.85 \mathrm{~mm}, \quad \mathrm{~L} 2=5.3 \mathrm{~mm}, \quad \mathrm{~W} 2=0.25 \mathrm{~mm}$, $\mathrm{S} 1=0.2 \mathrm{~mm}, \quad \mathrm{~S} 2=0.25 \mathrm{~mm}, \quad \mathrm{~W} 3=0.2 \mathrm{~mm}, \quad \mathrm{~L} 3=0.8 \mathrm{~mm}$, $\mathrm{W} 4=0.2 \mathrm{~mm}, \quad \mathrm{~L} 4=2.4 \mathrm{~mm}, \quad \mathrm{~L} 5=2.2 \mathrm{~mm}, \quad \mathrm{R} 1$ (radius of via) $=0.25 \mathrm{~mm}, \quad \mathrm{R} 2=0.4 \mathrm{~mm}, \quad \mathrm{~L} 6=1.65 \mathrm{~mm}, \quad \mathrm{~L} 7=0.4 \mathrm{~mm}$, $\mathrm{L} 8=0.5 \mathrm{~mm}, \mathrm{~L} 9=5.4 \mathrm{~mm}$. Filter is simulated with Ansoft HFSS with $50 \Omega$ matching impedence.
\end{abstract}

Fabricated filter with attached SMA connectors is photographed in Fig. 4 and it is measured using a Vector Network Analyzer. Fig. 5 shows simulated and measured results of the filter. Simulated results show that two stop bands with center frequencies of $8.3 \mathrm{GHz}$ and $12.9 \mathrm{GHz}$ are achieved with fractional bandwidths $57.8 \%$ and $32.5 \%$ respectively ( first stopband from $5.9 \mathrm{Ghz}$ to $10.7 \mathrm{Ghz}$ and second stopband from $10.8 \mathrm{Ghz}$ to $15 \mathrm{Ghz}$ ) ,there is small difference between measured and simulated data as second stopband in measured results is shifted $150 \mathrm{MHz}$ due to manufacturing possibilities . Insertion loss is less than $1 \mathrm{~dB}$ in upper and lower passbands, minimum simulated and measured attenuation at first stopband are $68 \mathrm{~dB}$ and $65 \mathrm{~dB}$ respectively, and at second stopband are $40 \mathrm{~dB}$ and $44 \mathrm{~dB}$ respectively.

The simulated group delay is less than $0.5 \mathrm{~ns}$ which is depicted in Fig. 6 and Fig. 7 shows the phase scattering parameters for S11 and S12 responses within the swept frequency range from 4 to $18 \mathrm{GHz}$ and within output phase angle range from -200 to 200 degrees. These responses include some frequency jumps which are the significant properties of elliptic filters. Accordingly, the intersection between $\mathrm{S} 11$ and $\mathrm{S} 21$ responses can be recognized easily, especially nearby resonant frequency. Filter has advantage of a compact size of $7.8 \mathrm{~mm} \times 15.1 \mathrm{~mm}$. Finally, comparison of results for several reported dual band BSFs [14-21] is shown in Table 1.

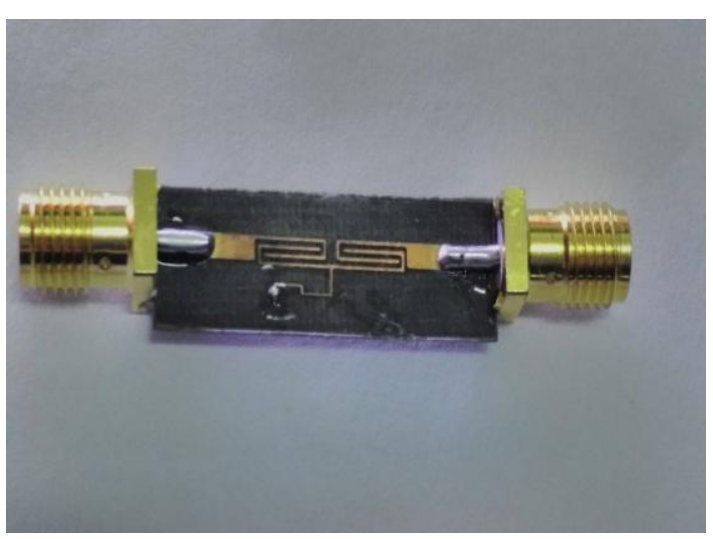

Fig. 4: Fabricated filter photograph

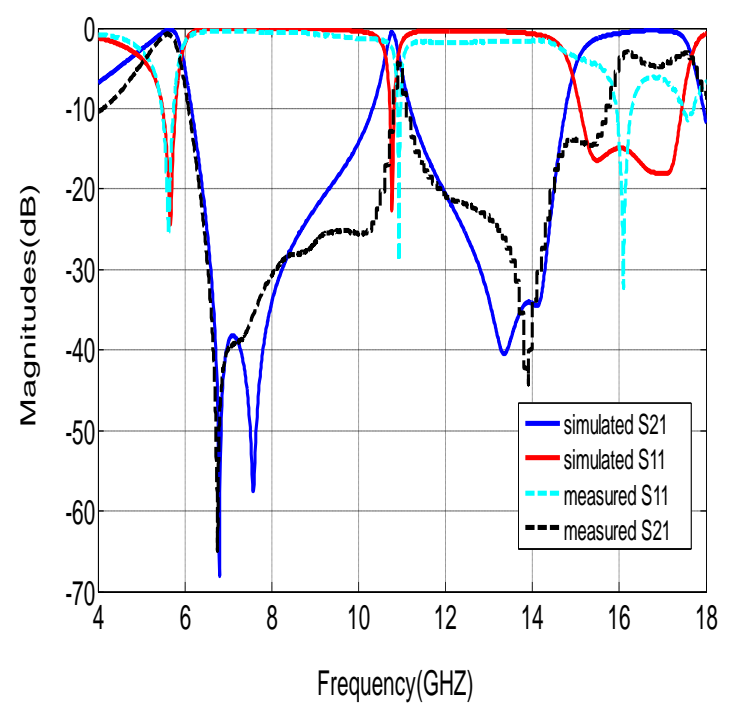

Fig .5: Simulated and measured results of a fabricated filter 


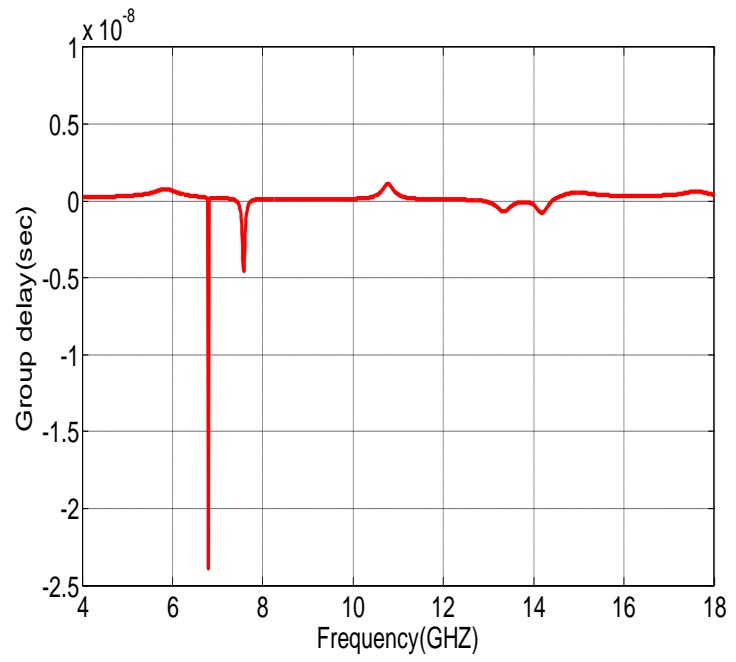

Fig .6:Simulated group delay of proposed dual BSF

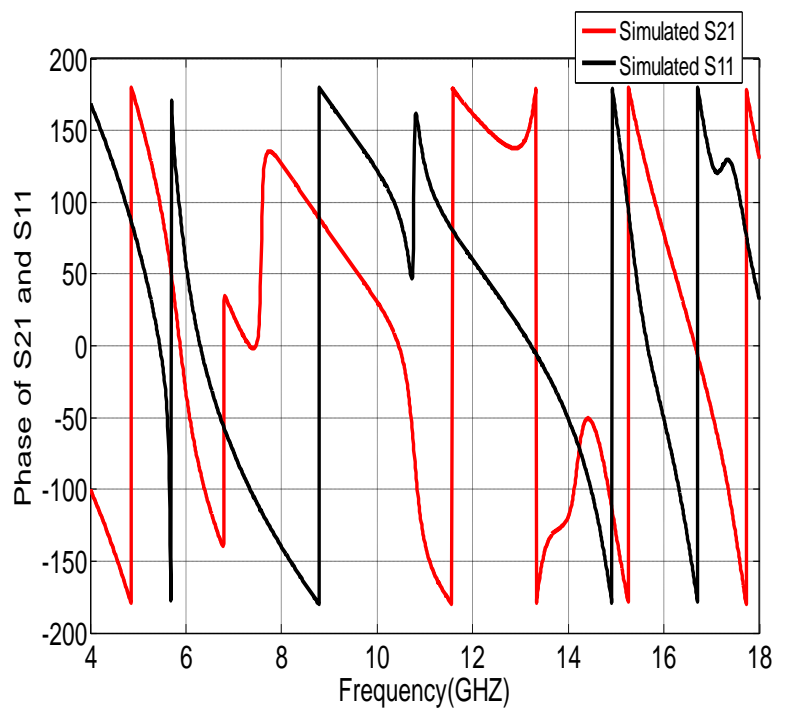

Fig .7: The Phase responses of proposed dual BSF

Table 1. Comparison with the reported dual band BSFs.

\begin{tabular}{|c|c|c|c|}
\hline Ref. & $\begin{array}{c}\text { First } \\
\text { Stopband } \\
\text { Freq (GHz) } \\
\text { / Rej (dB) }\end{array}$ & $\begin{array}{c}\text { Second } \\
\text { Stopband } \\
\text { Freq (GHz) } \\
\text { / Rej (dB) }\end{array}$ & $\begin{array}{c}\text { Passband } \\
\text { Performance }\end{array}$ \\
\hline$[14]$ & $1.5 / 39.8$ & $3.11 / 42$ & Normal \\
\hline$[15]$ & $2.1 / 37$ & $6.40 / 30$ & Normal \\
\hline$[16]$ & $2.12 / 19.4$ & $2.9 / 22.1$ & Normal \\
\hline$[17]$ & $2.37 / 31.4$ & $3.54 / 36.7$ & Good \\
\hline$[18]$ & $9.8 / 25$ & $11.35 / 25$ & Normal \\
\hline$[19]$ & $2.4 / 44$ & $3.7 / 34$ & Good \\
\hline$[20]$ & $2.52 / 30.5$ & $6.78 / 29.2$ & Normal \\
\hline$[21]$ & $2.0 / 35$ & $3.0 / 27$ & Normal \\
\hline $\begin{array}{c}\text { This } \\
\text { Work }\end{array}$ & $8.3 / 30.2$ & $12.9 / 40$ & Good \\
\hline
\end{tabular}

(Freq. and Rej. represent the center frequency and rejection level of the stopband correspondingly. Passband performance denotes the insertion losses and return losses of lower/middle/upper passbands).

\section{CONCLUSION}

A miniaturized wide dual band bandstop filter based on unbalanced composite right/left-handed transmission line has been proposed. The presented dual band bandstop filter is designed using spiral interdigital capacitors and stub inductors. Two stop bands with center frequencies of $8.3 \mathrm{GHz}$ and $12.9 \mathrm{GHz}$ are achieved with fractional bandwidths $57.8 \%$ and $32.5 \%$, respectively. The filter is designed, fabricated and measured. Results show agreement between simulation and measurement. The filter is low cost, very compact in size $(7.8 \mathrm{~mm} \times 15.1 \mathrm{~mm})$ and suitable for microwave communication systems. Multiband filters using CRLH-TLs and its modified models will be discussed in the future as multiband filters are important for different wireless and RFID applications.

\section{REFERENCES}

[1] A.Oliner, Jun. 2002 "A periodic-structure negativerefractive index medium without resonant elements," IEEE AP-S/URSI Int. Symp. Dig., pp. 41.

[2] C. Caloz ,\& T. Itoh, 2002 "Application of the transmission line theory of left-handed (LH) materials to the realization of a microstrip LH line," IEEE Antennas Propag. Symp. Dig.,pp. 412-415, San Antonio,TX.

[3] C. Caloz \& T. Itoh, 2006 "Electromagnetic Metamaterials: Transmission Line Theory and Microwave Application", John Wiley \& Sons.

[4] C. Caloz, H. Okabe, T. Iwai ,\&T. Itoh, Jun. 2002 "Transmission line approach of left-handed (lh)materials," IEEE AP-S/URSI Int. Symp. Dig., pp. 39.

[5] Cheng, D., H.-C. Yin ,\& H.-X. Zheng, "Investigation on a defected microstrip structure and applications in designing microstrip filters," Journal of Electromagnetic Waves and Application, Vol. 26, No. 10, pp.1332-1340, 2012.

[6] Cui, D., Y. Liu, Y. Wu, S. Li, \& C. Yu, “A compact bandstop filter based on two meandered parallel-coupled lines," Progress In Electromagnetics Research, Vol. 121,pp. 271-279, 2011.

[7] D. R. Smith, W. J. Padilla, D. C. Vier,\& et al., "Composite medium with simultaneously negative permeability and permittivity,". Physical Review Letters, vol.47, no.11, pp.2075-2084, Nov.1999.

[8] Isha Jindal, "Rejection of Multiple Interfering Bands Using stepped Impedance Resonators along the Feed Line", International Journal of Advanced Research in Computer and Communication Engineering ,Vol. 2, Issue 5, May 2013.

[9] J. B. Pendry, A. J. Holden, D. J. Robins, \& W. J. Stewart, "Magnetism from conductors and enhanced non linear phenomena," IEEE Trans. Microw. Theory Tech., vol.47, no.11, pp.2075-2048, Nov.1999.

[10] Jun WANG, Huansheng NING, Qingxu XIONG, Lingfeng MAO, “A Compact Narrow- Band Bandstop 
Filter Using Spiral shaped Defected Microsrip structure", Radio Engineering" Vol. 23, No. 1, April 2014.

[11] Lu, K.,2012 "Investigation into the design of novel metamaterial cells and their application in microwave engineering," Doctoral Dissertation, Air Force Engineering University of China, Xi'an.

[12] Song, J., X. Wang, X. You, \& B. Cheng, "Design of stripline bandstop filter using stepped-impedance resonator," Electronic Components \& Materials, Vol. 31, No. 9, pp.59-62, 2012.

[13] V. G. Veselago, "The electrodynamics of substances with simultaneously negative values of $\varepsilon$ and $\mu$," Soviet Physics USPEKI , vol.10, no.4, pp.509-514, Jan.Feb.1968.

[14] Chin, K.-S. and C.-K. Lung, "Miniaturized microstrip dual-band bandstop filters using tri-section steppedimpedance resonators," Progress In Electromagnetics Research C, Vol. 10, 37-48, 2009.

[15] Chiou, H.-K. and C.-F. Tai, "Dual-band microstrip bandstop filter using dual-mode loop resonator," Electron. Lett., Vol. 45, No. 10,507-509, 2009.

[16] Cheng, D., H.-C. Yin, and H.-X. Zheng, "A compact dual-band bandstop filter with defected microstrip slot,"
Journal of Electromagnetic Waves and Applications, Vol. 26, No. 10, 1374- 1380, 2012.

[17] Ning, H., J. Wang, Q. Xiong, and L. Mao, "Design of planar dual and triple narrow-band bandstop filters with independently controlled stopbands and improved spurious response," Progress In Electromagnetics Research, Vol. 131, 259-274, 2012.

[18] S. Fallahzadeh , H. Bahrami,and M. Tayarani,"A novel dual-band bandstop waveguide filter using split ring resonators," Progress In Electromagnetics Research Letters, Vol. 12, 133-139, 2009.

[19] Lei-Lei Qiu and Qing-Xin Chu "Compact and Sharprejection Dual-band Bandstop Filter Based on Transversal Signal-interaction Concept," Progress In Electromagnetics Research Symposium Proceedings, Guangzhou, China, Aug. 25-28, 1335-1338,2014.

[20] Gyan Raj KOIRALA, Nam-Young KIM "Multiband Bandstop Filter using an I-Stub-Loaded Meandered Defected Microstrip Structure" Radioengineering, Vol. 25, No 1, April 2016.

[21] Shujun Yang, "A Dual-Band Bandstop Filter Having Open Stubs and Two Equivalent T-Shaped Lines" International Journal of Electromagnetics and Applications 2015, 108-111. 